\title{
La consulta previa en la jurisprudencia constitucional de Colombia: Análisis de línea entre 1997-2015
}

\section{The prior consultation in the constitutional jurisprudence of Colombia: Line analysis between 1997-2015}

\begin{tabular}{ll}
\hline & Germán Cifuentes Sandoval' $\mid$ | Belinha Herrera Tapias ${ }^{2}$ Luz Mantilla Grande ${ }^{3}$ | Paola Carvajal Muñoz \\
\hline 1 & Candidato a Doctor en Derecho. Universidad Externado de Colombia. Correo electrónico: gcifuentes@yahoo.es \\
2 & Candidato a Doctor en Derecho. Universidad Externado de Colombia. Correo electrónico: bherrera3@cuc.edu.co \\
3 & Candidata a Magíster en Derecho de los Recursos Naturales de la Universidad Externado de Colombia. \\
& Correo electrónico: Imantillag@yahoo.es \\
4 & Magíster en Derecho Público y Ciencia Política de la Universidad del Zulia. Correo electrónico: pcarvaja1@cuc.edu.co \\
\hline
\end{tabular}

\section{RESUMEN}

A continuación, se presenta un estudio de línea jurisprudencial relacionado con el tratamiento judicial que la Corte Constitucional de Colombia ha dado en el periodo de tiempo 1997-2015 a la obligación de realizar consulta previa a las comunidades indígenas cuando se trate de la adopción de medidas legislativas que puedan afectar sus derechos (incluyendo aquellos relacionados con los recursos naturales existentes en sus territorios). La línea fue desarrollada conforme a la metodología propuesta por el profesor Diego López Medina (2006, p. 169). En su obra El derecho de los jueces y en caso de incorporación de cambios a la metodología precitada se hará la correspondiente observación a pie de página.

Palabras clave: Consulta previa, comunidades indígenas y línea jurisprudencial.

\section{ABSTRACT}

This article presents a jurisprudential line study related to the judicial treatment that Colombia's Constitutional Court has given between 1997 and 2015 to the obligation of consulting to the indigenous communities beforehand when it comes to adopt legislative measures that could affect their rights (including the ones related to existing natural resources in their territories). The line was developed just as the methodology proposed by the professor Diego Lopez Medina (2006, p. 169). In his book El derecho de los jueces and in the case of changes incorporation at the rushed methodology we will do the observation in the footnotes.

Keywords: Prior Consultation, indigenous communities and jurisprudential line.

\section{JUSTICIA}

ARTÍCULO DE

INVESTIGACIÓN

Recibido: 20-07-17

Aceptado: $13-09-17$

Publicado: 18-01-18

DOI: 


\section{INTRODUCCIÓN}

El presente artículo tiene por objetivo identificar, analizar y clasificar las formas como la Corte Constitucional ha resuelto el problema de la obligatoriedad de la consulta previa en el contexto del Convenio 169 de la Organización Internacional del Trabajo, OIT, particularmente en materia de medidas legislativas y no en el campo de medidas administrativas. Con él, no se pretende ahondar en el estudio normativo o doctrinal de la institución jurídica consulta previa, sino que se trata de evidenciar el mapa decisional que ha adoptado la Corte respecto de un problema fáctico concreto. Para este propósito el estudio se desarrollará de la siguiente forma:

\section{METODOLOGÍA}

En primer lugar, se hará una reconstrucción de los escenarios constitucionales dentro de los cuales se ha desarrollado el tratamiento judicial de la consulta previa en las decisiones de la Corte Constitucional. En este apartado se identificará un escenario central o de primer nivel para la consulta previa y luego se señalarán las posibles maneras como este puede desagregarse en un segundo nivel. Así mismo, se indicará cuál es el principal escenario normativo de la consulta previa en la Constitución Política de Colombia y se agruparán por años las sentencias que de manera general ha proferido la Corte en relación con el tema objeto de estudio.

En segundo lugar, se formulará el problema jurídico que habrá de orientar la construcción de la línea jurisprudencial y la elección de las sentencias que forman parte de ella. Para este propósito se precisarán las circunstancias fácticas que darán marco al escenario constitucional elegido, se formulará una pregunta de trabajo y se identificarán sus posibles soluciones u opciones polares de respuesta.

En tercer lugar, se procederá a la construcción de la línea conforme a la metodología propuesta en el Capítulo 5 del libro El derecho de los jueces de Diego López Medina (2006, p. 169). En este sentido, se identificará el punto arquimédico, se elaborará su nicho citacional de primer y segundo nivel, se clasificarán las sentencias identificadas en el nicho citacional indicando su nivel de citación, se graficará el mapa decisional o telaraña de la línea, y se identificarán los puntos nodales de decisión que la gobiernan.

Por último, se formularán las subreglas de derecho surgidas del derecho jurisprudencial de la Corte Constitucional para el problema específicamente planteado. 


\section{ESCENARIOS CONSTITUCIONALES DE LA CONSULTA PREVIA EN COLOMBIA: NIVELES 1 Y 2}

La consulta previa en Colombia conforma una garantía constitucional surgida del reconocimiento de la diversidad cultural, étnica, ambiental y social existente en el territorio nacional. Colombia está integrada en mayor número por habitantes que desarrollan su estilo de vida a la usanza de la "cultura occidental," pero también conviven en ella múltiples comunidades humanas que, a pesar de ser minoritarias, conservan su identidad y se mantienen ajenas a las costumbres y hábitos sociales que la mayor parte de la población emplea regularmente.

Consciente de la coexistencia étnica y en reconocimiento de los aportes vitales efectuados por estas comunidades a la edificación de la nación colombiana, el Constituyente de 1991 incorporó al texto constitucional un conjunto de normas destinadas a la protección de la identidad cultural, la diversidad étnica, la autonomía territorial, la propiedad colectiva, la autodeterminación y los derechos humanos de estas comunidades. Adicionalmente, en el contexto del derecho internacional y del bloque de constitucionalidad la Constitución Política de Colombia incorporó al sistema jurídico colombiano el Convenio 169 de la OIT como piedra angular de la defensa de los derechos de las minorías étnicas. El Convenio y la Constitución establecen de forma armónica un conjunto de mecanismos para la defensa de sus derechos dentro de los cuales se incorpora, de un lado, la obligación del Estado de consultar de manera previa a las comunidades acerca de la adopción de medidas legislativas y administrativas que puedan afectar su condición de minoría étnica y, de otro, el derecho de las comunidades a opinar y decidir sobre las mismas en condiciones igualitarias a las demás agrupaciones humanas que integran el territorio.

Ha sido frecuente la intervención del Poder Judicial para dirimir las múltiples controversias que de la interpretación de las normas constitucionales pertinentes surgen en la práctica. Si bien la Carta Política contiene un conjunto de normas relativas a los derechos de las comunidades étnicas, particularmente los artículos 1, 7 y 330 ofrecen fuerte fundamento para exigir el cumplimiento de la obligación estatal de consultar a las poblaciones indígenas y, que algunas normas de carácter legal han replicado su necesaria realización (entre ellas la L. 70/1993, L.99/1993, L.165/1994 y L.1437/2011).

El ordenamiento normativo colombiano no ha establecido con especificidad 
un instrumento jurídico vinculante de carácter legal ${ }^{5}$ que con fundamento en el Convenio 169 de la OIT (ratificado por Colombia mediante L.21/1991) precise materias tales como los eventos en los cuales es obligatoria la realización de la consulta y en cuales no, el debido proceso para la materialización del deber de consultar, el alcance de la expresión "afectación directa" contenida en el Convenio de la OIT, los límites al derecho de consulta, las consecuencias de la falta de acuerdo en el proceso de consulta, las sanciones por inaplicación de la obligación de consulta o por implementar medidas diferentes a las legítimamente acordadas con las comunidades, los principios rectores, la delimitación de las áreas geográficas, y los sujetos activos y pasivos del derecho-obligación de consulta.

Ante esta gran cantidad de carencias normativas que no han sido satisfechas por el legislador colombiano y, que no pueden ser resueltas por la OIT por tratarse de asuntos que han sido dejados a la potestad interna de cada Estado en ejercicio de sus atribuciones soberanas, se han suscitado múltiples controversias entre las autoridades legislativas y administrativas, de un lado, y las comunidades étnicas, de otro.

Para este propósito la Corte Constitucional en ejercicio de sus funciones constitucionales y legales ha resuelto por vía de sentencia acciones de tutela, acciones de inconstitucionalidad y revisiones automáticas de leyes y actos legislativos en las que ha establecido un conjunto de subreglas, útiles y necesarias, para llenar los vacíos legislativos. Así, se han debatido fundamentalmente cuatro aspectos que podrían considerarse componentes del escenario constitucional principal (o primer nivel) de la consulta previa en Colombia.

En primera instancia, se ha analizado el alcance de la consulta previa como un derecho fundamental autónomo de las comunidades étnicas y como una obligación constitucional a cargo del Estado colombiano.

En segundo lugar, se han estudiado las clases de derechos que pueden ser protegidos mediante la realización de la consulta previa diferenciando el derecho fundamental a la consulta, de los derechos que se regulan dentro de la misma. Aquí, se incluye el tratamiento que se da a los derechos a la

5 Teniendo en cuenta que el derecho de consulta previa a las comunidades étnicas tiene carácter de derecho fundamental consideramos que la manera constitucional de desarrollar el mencionado derecho debe ser mediante la aprobación de una ley estatutaria, sin embargo el Congreso de la República ha guardado silencio hasta la fecha de hoy y en vez de emplearse una norma de dicha jerarquía se está acudiendo a las orientaciones previstas en las Directivas presidenciales 01 de 2010 y 10 de 2013, solución que en estricto sentido resulta ser muy dudosa por la naturaleza jurídica de dichas "normas" y por la vinculatoriedad que estas pueden llegar a ejercer sobre un derecho fundamental. 
diversidad étnica y cultural; los derechos de participación, representación y elección en cargos públicos; el derecho a la autodeterminación de los pueblos; $y$, otros tipos de derechos como la libertad religiosa, la educación y el libre desarrollo de la personalidad.

En tercera medida, se ha analizado el procedimiento como se debe efectuar el trámite de la consulta previa. Allí se observan aspectos relacionados con la delimitación de la zona geográfica para la realización de la consulta, el momento para su solicitud y realización, la legitimación para solicitar la consulta y participar en ella, la etapa preconsultiva, y, las actividades que conforman su desarrollo y dentro de las que habrá de participar la comunidad para tenerla por surtida.

Por último, la Corte ha estudiado los efectos de las decisiones surgidas de la realización de la consulta previa y allí se han incluido reflexiones acerca de las implicaciones de la falta de acuerdo, las consecuencias del desconocimiento o mutación de los acuerdos, y, el cumplimiento posterior de los acuerdos efectuados.

Con base en estos posibles escenarios de primer nivel, el escenario constitucional fundamental de la consulta previa en Colombia podría representarse así:

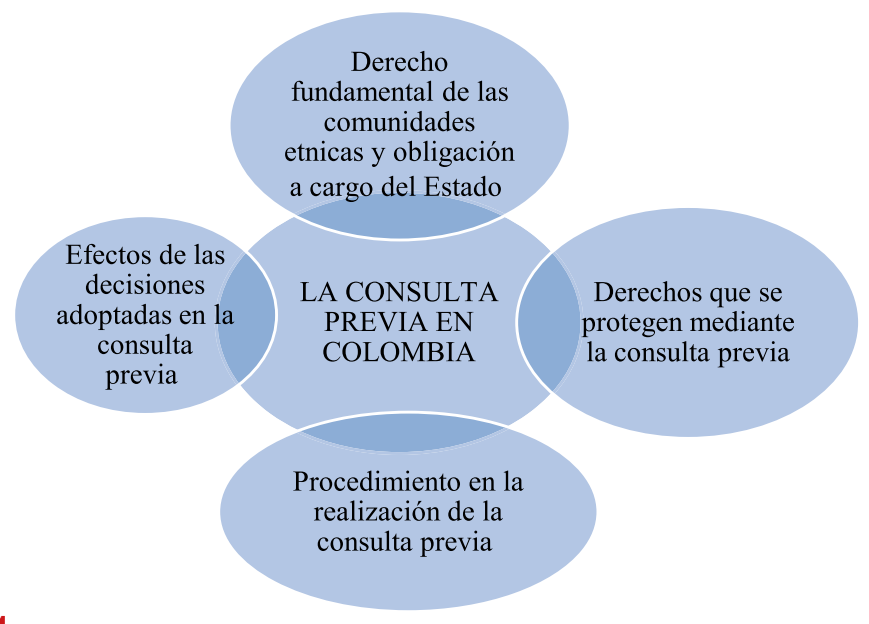

Figura No. 1.

Fuente propia

En este punto se ha de aclarar, con el ánimo de resaltar la importancia que la Corte ha dado al tema de la consulta previa, que es frecuente encontrar en las sentencias del Tribunal Constitucional de Colombia discusiones simultáneas sobre varios de los escenarios constitucionales. Así por ejemplo, señala la 
Corte en Sentencia T-382 de 2006 al revisar una acción de tutela incoada por la Asociación de Autoridades Tradicionales del Consejo Regional Indígena del Medio Amazonas -CRIMA- en contra del Congreso de la República, el Ministerio de Ambiente, Vivienda y Desarrollo Territorial y el Ministerio de Agricultura y Desarrollo Rural por el trámite de un proyecto de ley forestal que estaba siendo debatido sin que se hubiesen desarrollado las respectivas consultas a las comunidades indígenas, que:

Los escenarios en los que podemos agrupar el desenvolvimiento del derecho de consulta previa son: el primero, la construcción de la iniciativa gubernamental antes de presentar el texto ante el Congreso; el segundo se refiere, en estricto, a la eficacia del derecho durante el trámite de un proyecto de ley y, el tercero, aplica a la práctica del derecho en sede administrativa, cuando se ejecutan actos específicos o individuales que puedan afectar o interesar a las comunidades indígenas, v. g. la expedición de una licencia ambiental, la constitución de una concesión, la ejecución de un programa de fumigación de cultivos ilícitos o la contratación de una obra. (p. 15)

Anótese cómo en la providencia recién mencionada confluyen varios escenarios constitucionales de primer y segundo nivel. En primer lugar, se analizan los hechos a la luz del derecho fundamental de las comunidades indígenas a la realización de una consulta previa por la adopción de una medida legislativa que puede afectar los recursos naturales presentes en su territorio. En segundo lugar, se plantea una controversia acerca de si la acción de tutela procede cuando en el trámite de un proyecto de ley que aún no ha concluido, se ha vulnerado el derecho fundamental a la consulta previa. Y en tercer lugar, se analizan las posibles vulneraciones a los derechos a la vida, la integridad del territorio y la identidad cultural. Esta coexistencia de escenarios constitucionales no es, sin embargo, un error metodológico de la Corte. Por el contrario, resalta la complejidad e importancia del tema y sugiere la necesidad de análisis multiniveles e interrelacionados.

A manera de síntesis podría decirse entonces que los escenarios constitucionales de primer y segundo nivel de la consulta previa conforme con el tipo de controversias que resuelve la Corte Constitucional de Colombia pueden representarse así: 


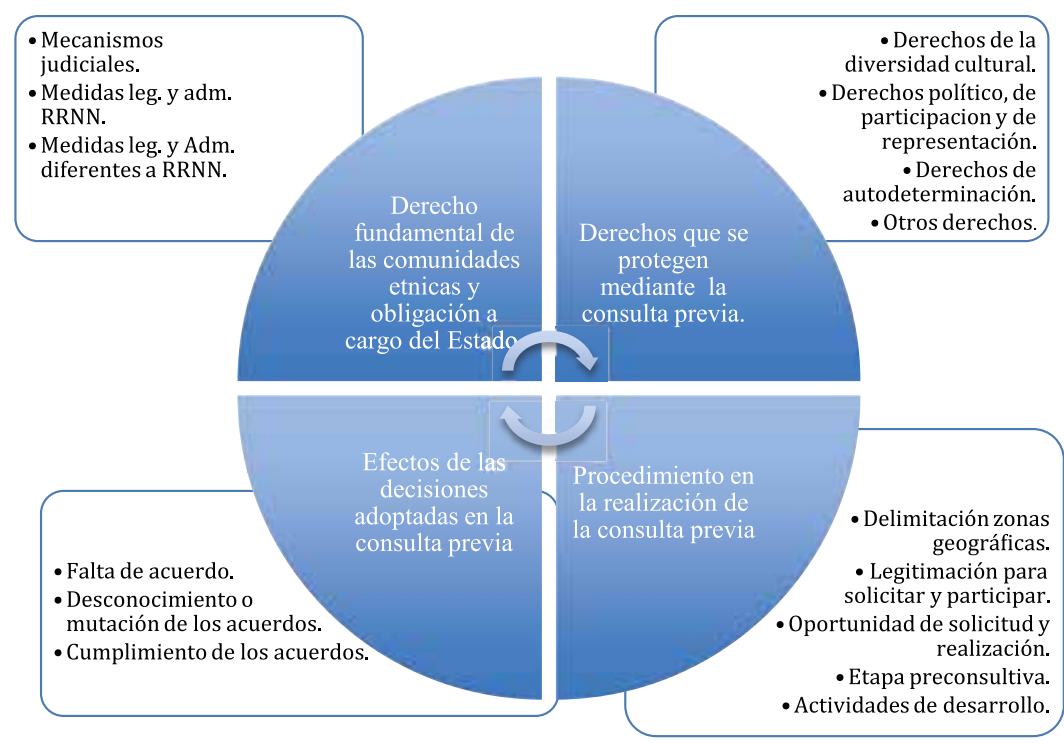

Figura No. 2. Derechos fundamentales de las comunidades étnicas

Fuente propia

En cuanto al escenario normativo constitucional de la consulta previa en Colombia pueden indicarse como principales artículos que enmarcan las dimensiones antes expuestas los siguientes:

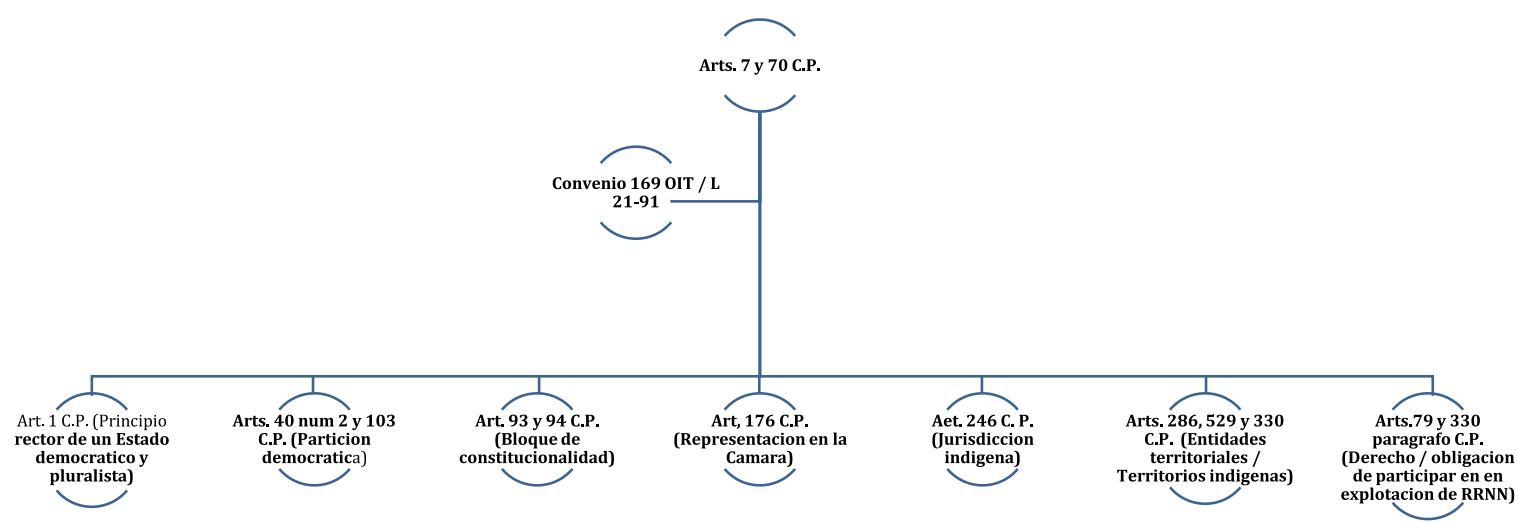

Figura No. 3. Consulta previa

Fuente propia

Por último, a manera de resumen, pueden citarse, como nicho citacional abstracto de la consulta previa en Colombia, las siguientes sentencias de la Corte Constitucional, aclarando que las providencias aquí reseñadas corresponden a los resultados arrojados por la base de datos de la relatoría de la Corte al buscar por el descriptor consulta previa. 
Tabla 1. Línea jurisprudencial

\begin{tabular}{|c|c|c|c|c|c|c|c|}
\hline 1992 & 1993 & 1994 & 1995 & 1996 & 1997 & 1998 & 1999 \\
\hline $\operatorname{Sin} C$ & $\operatorname{Sin} C$ & $\operatorname{Sin} C$ & $\operatorname{Sin} C$ & $\operatorname{Sin} C$ & $\operatorname{Sin} C$ & $\operatorname{Sin} C$ & $\operatorname{Sin} C$ \\
\hline $\operatorname{Sin} T$ & $\operatorname{Sin} T$ & $\operatorname{Sin} T$ & $\operatorname{Sin} T$ & $\operatorname{Sin} T$ & $\operatorname{Sin} T$ & T-652 & $\mathrm{T}-143$ \\
\hline \multirow[t]{2}{*}{$\operatorname{Sin} S U$} & \multirow[t]{2}{*}{$\operatorname{Sin} S U$} & \multirow[t]{2}{*}{$\operatorname{Sin} S U$} & \multirow[t]{2}{*}{$\operatorname{Sin} S U$} & \multirow[t]{2}{*}{$\sin S U$} & \multirow[t]{2}{*}{$\operatorname{Sin} S U$} & \multirow[t]{2}{*}{$\operatorname{Sin} S U$} & T-634 \\
\hline & & & & & & & $\operatorname{Sin} S U$ \\
\hline 2000 & 2001 & 2002 & 2003 & 2004 & 2005 & 2006 & 2007 \\
\hline $\operatorname{Sin} C$ & C-169 & C-418 & C-620 & C-245 & $\operatorname{Sin} C$ & $\operatorname{Sin} C$ & C-208 \\
\hline $\operatorname{Sin} T$ & $\operatorname{Sin} T$ & $\operatorname{Sin} T$ & T-955 & $\operatorname{Sin} T$ & $\operatorname{Sin} T$ & T-382 & $\operatorname{Sin} T$ \\
\hline \multirow{2}{*}{$\operatorname{Sin} S U$} & \multirow[t]{2}{*}{$\operatorname{Sin} S U$} & \multirow[t]{2}{*}{$\operatorname{Sin} S U$} & \multirow[t]{2}{*}{ SU-383 } & \multirow[t]{2}{*}{$\operatorname{Sin} S U$} & \multirow[t]{2}{*}{$\operatorname{Sin} S U$} & T-880 & \multirow[t]{2}{*}{$\operatorname{Sin} S U$} \\
\hline & & & & & & $\operatorname{Sin} S U$ & \\
\hline 2008 & 2009 & 2010 & 2011 & 2012 & 2013 & 2014 & 2015 \\
\hline C-030 & C-175 & C-063 & C-027 & C-051 & C-068 & C-133 & C-150 \\
\hline C-038 & C-290 & C-608 & C-187 & C-196 & C-194 & C-269 & C-163 \\
\hline C-461 & C-615 & C-702 & C-366 & C-293 & C-253 & C-313 & C - -217 \\
\hline C-750 & T-154 & C-915 & C-367 & C-317 & C-274 & C-332 & $\operatorname{Sin} T$ \\
\hline $\operatorname{Sin} T$ & T-769 & C-941 & C-490 & C-318 & C-350 & C-371 & $\operatorname{Sin} S U$ \\
\hline \multirow[t]{22}{*}{$\operatorname{Sin} S U$} & \multirow[t]{22}{*}{$\sin S U$} & $\mathrm{~T}-063$ & C-748 & C-331 & C-359 & C-501 & \\
\hline & & T-547 & C-882 & C-395 & C-616 & C-948 & \\
\hline & & T-745 & C-937 & C-398 & C-622 & C-951 & \\
\hline & & T-1045a & T116 & C-540 & C-909 & T-204 & \\
\hline & & $\operatorname{Sin} S U$ & T-129 & C-641 & T-049 & T-294 & \\
\hline & & & T-379 & C-765 & T-172 & T-353 & \\
\hline & & & T-601 & C-767 & $\mathrm{T}-245$ & T-355 & \\
\hline & & & $\mathrm{T}-693$ & C-822 & T-300 & T-396 & \\
\hline & & & T-698 & C-862 & T-657 & T-462 & \\
\hline & & & $\sin S U$ & C-943 & T-795 & T-576 & \\
\hline & & & & C-1051 & T-858 & T-646 & \\
\hline & & & & T-348 & $\operatorname{Sin} S U$ & T-800 & \\
\hline & & & & T-376 & & $\operatorname{Sin} S U$ & \\
\hline & & & & T-477 & & & \\
\hline & & & & T-513 & & & \\
\hline & & & & T-514 & & & \\
\hline & & & & T-680 & & & \\
\hline & & & & T-693 & & & \\
\hline & & & & T-823 & & & \\
\hline & & & & T-993 & & & \\
\hline & & & & T-1080 & & & \\
\hline & & & & $\operatorname{Sin} S U$ & & & \\
\hline
\end{tabular}




\section{DETERMINACIÓN CONCRETA DEL PROBLEMA JURÍDICO A PARTIR DE LA ELECCIÓN DE UN ESCENARIO CONSTITUCIONAL ESPECÍFICO}

\section{A. Consideraciones fácticas aplicables a la elección del escenario constitucional y a la formulación del problema}

Partiendo de que el escenario constitucional elegido para el desarrollo inicial de la línea es el de la obligatoriedad de la consulta previa como derecho fundamental de las comunidades indígenas en la adopción de medidas legislativas que puedan afectar sus derechos, se establecen como presupuestos fácticos que gobernarán el análisis de línea las siguientes consideraciones:

- La Constitución Política establece el derecho fundamental de las comunidades indígenas a la consulta previa cuando se trate de la adopción de medidas legislativas que tengan relación con los recursos naturales existentes en sus territorios.

- Colombia es un país megadiverso y su gran diversidad ambiental, étnica, cultural y social se encuentra presente en todo el territorio nacional.

- Muchos componentes de la diversidad ambiental étnica, cultural y social de Colombia se encuentran presentes de manera conjunta y simultánea en territorios indígenas y en territorios no indígenas.

- Muchos componentes de la diversidad ambiental, étnica, cultural y social de Colombia se encuentran presentes de manera exclusiva en territorios indígenas.

- Los componentes de la diversidad ambiental se encuentran fuertemente ligados a la identidad cultural y étnica de las comunidades indígenas.

- En la práctica el Estado colombiano ha adoptado medidas legislativas que pudiendo afectar la diversidad ambiental, étnica, cultural y social existente en territorios indígenas, no han sido consultadas a las comunidades que allí habitan.

- En Colombia existen además de las comunidades indígenas otras comunidades étnicas como las afrodescendientes y raizales, entre otras.

- Las comunidades étnicas (indígenas, afrodescendientes y raizales) mantienen un estilo de vida que se manifiesta no solo en sus derechos sobre los recursos naturales, sino sobre otros tipos de derechos que podrían resultar afectados por la adopción de medidas legislativas no consultadas.

- Colombia ratificó mediante Ley 21 de 1991 el Convenio 169 de la OIT sobre pueblos indígenas y tribales. 


\section{B. Formulación del problema y de las opciones polares de respuesta}

Como punto de partida, la Corte Constitucional ha debatido en múltiples ocasiones la obligatoriedad de la consulta previa a las comunidades indígenas en la adopción de medidas legislativas que puedan afectar los recursos naturales existentes en sus territorios. Así, en el marco de este escenario surge una interrogante inicial en el sentido de determinar si la consulta previa es obligatoria en toda situación que implique la toma de medidas legislativas que estén relacionadas con la explotación de sus recursos naturales, o si, en ciertos casos no es obligatorio consultar; y, unas interrogantes subsiguientes en las que se ha debatido acerca de si la obligación de consulta solo aplica para temas relacionados con recursos naturales o si su ámbito es más amplio y opera igualmente en cualquier tipo de medida que pueda afectar su condición étnica o cultural; $y$, si la consulta previa está destinada únicamente a las comunidades indígenas del territorio nacional o pueda afectar otros grupos étnicos como afrodescendientes o raizales.

En este punto y ubicándonos en la interrogante inicial antes identificada por pertenecer al escenario constitucional del parágrafo del artículo 330 superior, es necesario aclarar en torno a la pregunta que a continuación se formula y sus opciones polares de respuesta (OP1 y OP2) que, aunque la norma recién mencionada establece la obligación de realizar la consulta previa en todos aquellos casos de explotación de recursos naturales existentes en los territorios de las comunidades indígenas, la jurisprudencia de la Corte Constitucional ha señalado que la obligación de consulta aplica no solo en materia de explotación o afectación a los recursos naturales sino también en casos de afectación a los derechos de las comunidades étnicas existentes en Colombia.

Así, y aunque antes se ha hecho referencia a una interrogante inicial y dos interrogantes subsecuentes que evidentemente amplían el escenario fáctico y conceptual de la línea en desarrollo, formularemos a continuación una pregunta referida al criterio preponderante de interpretación de la consulta previa en cuanto derecho-obligación aplicable en todo tipo de medida legislativa. Con este propósito ha de decirse que la pregunta planteada a continuación ofrece principalmente tres posibles posiciones en torno de las cuales la jurisprudencia constitucional ha analizado las posibles respuestas, sin que esto, por supuesto, impida de ningún modo la existencia de otras posibles 
posturas intermedias o conexas que graviten en medio de las posturas principales, y que resulten evidentes en el desarrollo de la línea.

En primer lugar, se encuentra la solución prevista en OP1 en la que la obligación de consulta es general para todo tipo de medida legislativa que pueda implicar afectación a los derechos de las comunidades étnicas. En esta postura, la obligación depende fundamentalmente del hecho de que los destinatarios de las medidas legislativas puedan ser las comunidades étnicas. No se analiza la efectiva vulneración de derechos, sino que se tiene en cuenta la posible afectación que de la implementación de una medida general pueda materializarse sobre las comunidades étnicas.

En segundo lugar, se encuentra una de las dos soluciones iniciales que nacen de OP2 (1 ${ }^{\text {a }}$ OP 2), según la cual la obligación de consulta de medidas legislativas surge en aquellos casos de afectación directa de los derechos de las comunidades étnicas. En esta posición impera un criterio de valoración sobre las medidas a adoptar dentro del cual el Estado debe sopesar las posibles consecuencias reales y directas para los derechos de las comunidades étnicas y conforme a las conclusiones que de allí surjan, optar por consultarlas o no. Esta solución si bien se encuentra en la zona de influencia de OP2 se ubica hacia el centro del mapa decisional de la Corte porque a pesar de contemplar la necesidad de valoración de las consecuencias de las medidas a adoptar, tiende hacia una protección del derecho a la consulta similar a la propuesta en OP1 en el sentido de considerar obligatoria la consulta siempre que de las medidas surja afectación directa a los hábitos de vida de las comunidades.

En tercer lugar, se plantea la otra solución que nace inicialmente de OP2 ( $2^{\mathrm{a}}$ OP 2) en la que se contempla que la obligación de consulta a las comunidades indígenas no se materializa cuando las medidas legislativas a adoptar no constituyan afectaciones ciertas y directas a los derechos de las comunidades por tratarse de medidas de contenido abstracto o general que no afectan por sí mismas a ninguna comunidad o población en particular o específica. La pregunta planteada y las opciones polares de respuesta con las dos posturas señaladas inicialmente para OP 2, podrían graficarse así: 

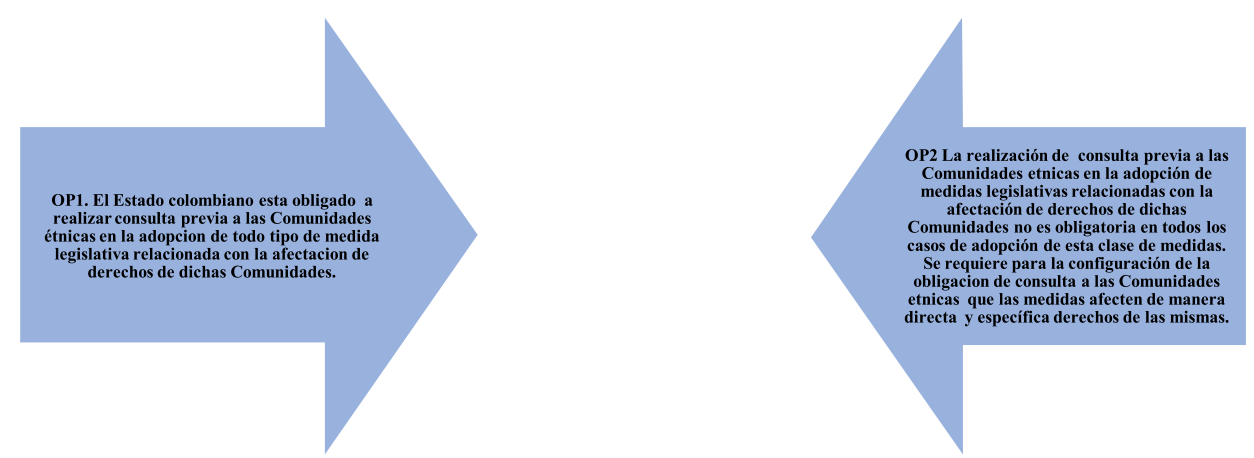

Figura No. 4. Comunidades étnicas

Fuente propia

\section{CONSTRUCCIÓN DE LA LÍNEA JURISPRUDENCIAL}

\section{A. Punto arquimédico y nicho citacional de primer nivel (Ingeniería reversa de primer nivel)}

Siguiendo la metodología elegida para la construcción de la línea se encontró que la sentencia más reciente proferida por la Corte Constitucional en materia de medidas legislativas adoptadas por el Estado colombiano con posibles implicaciones para las comunidades étnicas y por tanto, sometida a la obligación genérica de realización de consulta previa es la C-163 de 2015, la cual fungirá como punto arquimédico de la línea. Además, después de haber verificado su contenido se encontró que en la misma se hace referencia a las siguientes sentencias relacionadas con el problema jurídico planteado: C-332 de 2014, C-615 de 2009, C-175 de 2009, C-750 de 2008, y, C-030 de 2008, las cuales conformarán el nicho citacional de primer nivel de la línea en construcción.

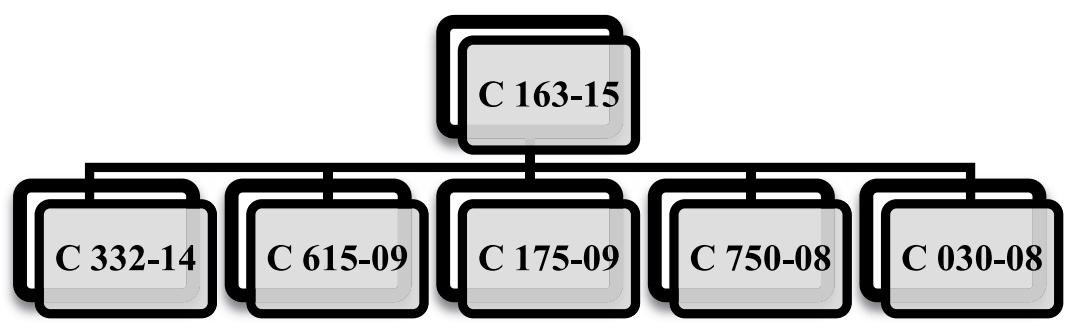

Figura No. 5. Nicho citacional de primer nivel

Fuente propia

A continuación, y con la revisión de las cinco sentencias que conforman el nicho citacional de primer nivel, pudo conformarse un nicho citacional de segundo nivel, el cual se indica a continuación y servirá para la construcción de la telaraña (o mapa decisional de la Corte) y para la identificación de los puntos nodales de decisión, aclarando que para los fines prácticos del presente 
análisis no se consideró necesario edificar nichos citacionales de tercer o cuarto nivel dada la contundencia con que la Corporación ha manejado el tema desde la expedición de la sentencia SU-039 de 1997.

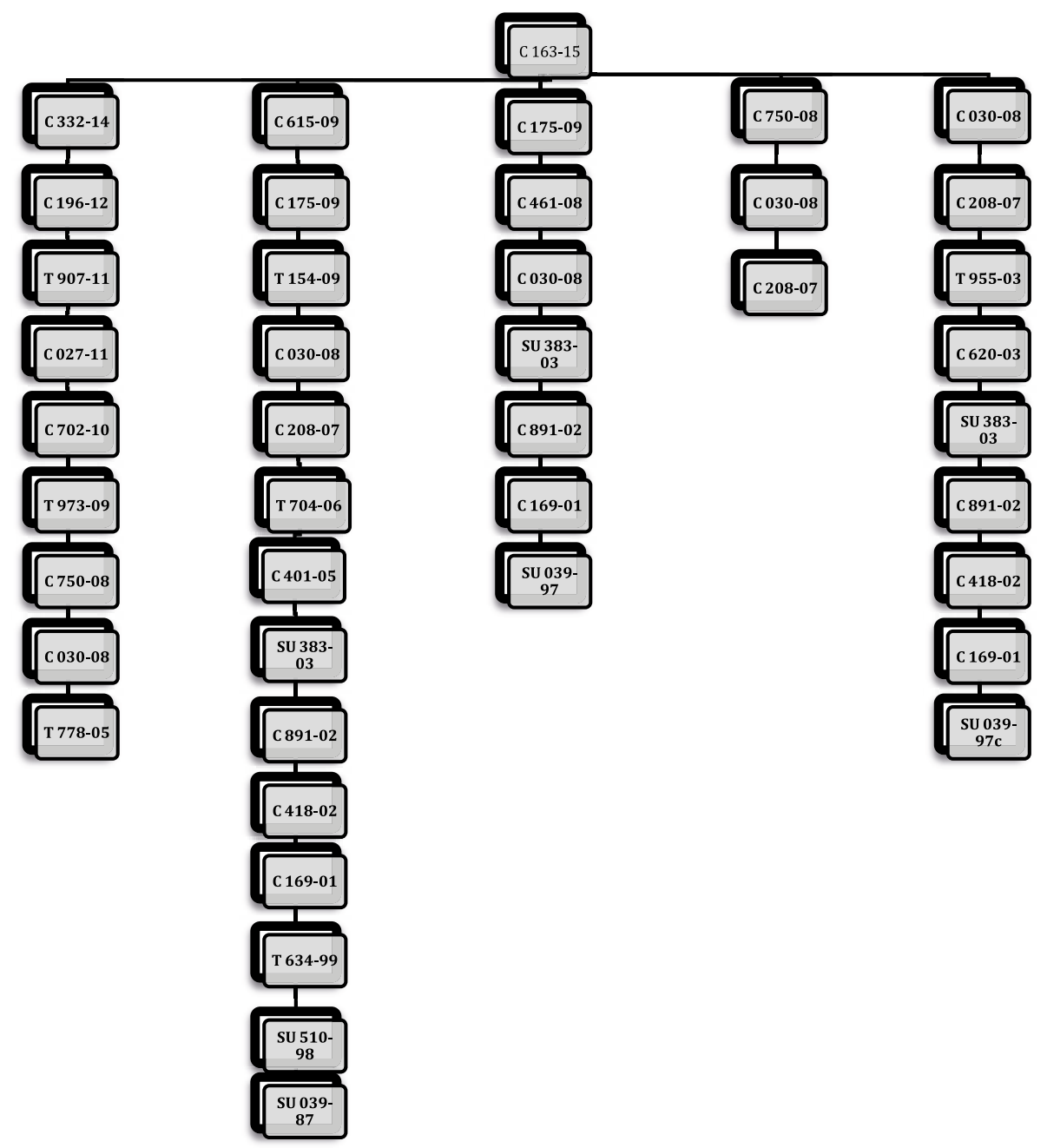

Figura No. 6. Línea jurisprudencial

Fuente propia

Renglón seguido se clasificaron las sentencias identificadas en el punto arquimédico y en los dos primeros niveles del nicho citacional ${ }^{6}$ y se agruparon como:

1. Sentencias fundadoras de línea de tipo general: SU-039-97.

2. Sentencias hito fundadoras de línea: C-169-01, C-418-02, SU- 383-03.

6 La intensidad del sombreado que se emplea en la Tabla que sigue indica el nivel de citación de cada una de las sentencias aquí indicadas. Las sentencias que aparecen señaladas con el tono más oscuro son aquellas que mayor número de veces fueron citadas. Las sentencias que aparecen sin ningún tipo de sombreado solo fueron citadas una vez. Por último, las sentencias resaltadas en tonos intermedios fueron citadas regularmente. 
3. Sentencias hito consolidadoras de línea: C-030-08, C-461-08, C-750-08, C-175-09.

4. Sentencias hito dominantes: C-030-08.

5. Sentencias de confirmación: C-891-02, C-208-07, C-615-09, C-702-10, C-027-11, C-196-12, C-332-14, C-163-15.

6. Sentencias no relevantes: SU-510-98, T-634-99, C-620-03, T-955-03, C-401-05, T-778-05, T-704-06, T-154-09, T-973-09, T-907-11.

Tabla 2

\begin{tabular}{|c|c|c|c|}
\hline $\begin{array}{l}\text { SENTENCIAS } \\
\text { FUNDADORAS } \\
\text { (En general) }\end{array}$ & $\begin{array}{c}\text { SENTENCIAS HITO } \\
\text { (Fundadoras Fd. Consolidación Cs } \\
\text { Dominante D) }\end{array}$ & $\begin{array}{l}\text { SENTENCIAS DE } \\
\text { CONFIRMACIÓN }\end{array}$ & $\begin{array}{l}\text { SENTENCIAS NO } \\
\text { RELEVANTES }\end{array}$ \\
\hline SU 039-97 & $\begin{array}{c}\text { C 169-01 (Fd) } \\
\text { C 418-02 (Fd) } \\
\text { SU 383-03 (Fd) } \\
\text { C 030-08 (Cs y D) } \\
\text { C 461-08 (Cs) } \\
\text { C 750-08 (Cs) } \\
\text { C 175-09 (Cs) }\end{array}$ & $\begin{array}{l}\text { C 891-02 } \\
\text { C 208-07 } \\
\text { C 615-09 } \\
\text { C 702-10 } \\
\text { C 027-11 } \\
\text { C 196-12 } \\
\text { C 332-14 } \\
\text { C 163-15 }\end{array}$ & $\begin{array}{c}\text { SU 510-981 } \\
\text { T 634-992 } \\
\text { C } 620-03^{3} \\
\text { T } 955-03^{4} \\
\text { C } 401-05^{5} \\
\text { T } 778-05^{6} \\
\text { T } 704-06^{7} \\
\text { T } 154-09^{8} \\
\text { T } 973-09^{9} \\
\text { T } 907-11^{10}\end{array}$ \\
\hline 1 & \multicolumn{3}{|c|}{$\begin{array}{l}\text { No es relevante para el caso en concreto por analizar los alcances del derecho a la libertad de cultos de los integrantes de la } \\
\text { Comunidad Arhuaco. }\end{array}$} \\
\hline 2 & \multicolumn{3}{|c|}{$\begin{array}{l}\text { No es relevante para el caso en concreto por analizar actos administrativos sobre la creación de un municipio en el Cesar sin tener } \\
\text { presuntamente en cuenta al pueblo Arhuaco. }\end{array}$} \\
\hline 3 & \multicolumn{3}{|c|}{$\begin{array}{l}\text { No es relevante para el caso en concreto toda vez que no guarda relación directa con los presupuestos facticos que enmarcan la } \\
\text { línea. Si bien se debate acerca de la explotación de sal en territorios con presencia de Comunidades indígenas, se analiza la supuesta } \\
\text { violación del derecho a la igualdad y la existencia de vicios de forma en el procedimiento legislativa de creación de la ley. }\end{array}$} \\
\hline 4 & \multicolumn{3}{|c|}{$\begin{array}{l}\text { No es relevante para el caso en particular por referirse a la implementación de medidas administrativas en explotaciones madereras } \\
\text { del rio Cacarica (Choco) }\end{array}$} \\
\hline 5 & \multicolumn{3}{|c|}{$\begin{array}{l}\text { No es relevante para caso en concreto por analizar la constitucionalidad de una expresión contenida en el Código sustantivo del } \\
\text { trabajo relacionada con la aplicación de normas supletorias en el contrato de trabajo. }\end{array}$} \\
\hline 6 & \multicolumn{3}{|c|}{$\begin{array}{l}\text { No es relevante para el caso en concreto por dedicarse al estudio de una presunta violación a los derechos a la identidad cultural y } \\
\text { representación política de Comunidades étnicas por causa de una acción de nulidad electoral en contra de un Concejal de Bogotá. }\end{array}$} \\
\hline 7 & \multicolumn{3}{|c|}{$\begin{array}{l}\text { No es relevante para este caso en concreto por referirse a la implementación de medidas administrativas que afectan a Comunidades } \\
\text { Wayuu en materia de distribución de recursos económicos. }\end{array}$} \\
\hline 8 & \multicolumn{3}{|c|}{$\begin{array}{l}\text { No es relevante para el caso en concreto por analizar la supuesta violación de derechos de la Comunidad Wayuu en la expedición de } \\
\text { una licencia ambiental para construcción de una represa y un distrito de riego. }\end{array}$} \\
\hline 9 & \multicolumn{3}{|c|}{$\begin{array}{l}\text { No es relevante para el caso en concreto por dedicarse al estudio de actos administrativos relacionados con el ejercicio de los } \\
\text { derechos a la diversidad étnica y a la autonomía política de las comunidades indígenas en una controversia por la elección del } \\
\text { Gobernador de la Etnia Kametsa. }\end{array}$} \\
\hline$T$ & \multicolumn{3}{|c|}{$\begin{array}{l}\text { No es relevante para el caso en concreto por estar dedicada al análisis de actos administrativos relacionados con los derechos } \\
\text { a la educación de las Comunidades indígenas y a su auto determinación en razón de nombramientos docentes para el resguardo } \\
\text { Kakiona (Cauca). }\end{array}$} \\
\hline
\end{tabular}

Con fundamento en la selección de sentencias hecha en la fase anterior y retomando el problema jurídico planteado y sus dos opciones polares de respuesta, se procedió a elaborar la telaraña de la línea en la que, como indica el profesor López Medina (2006, p. 169), se posiciona la pregunta en el encabezado de la gráfica, se ubican las opciones polares de respuesta en los extremos, se localizan las sentencias seleccionadas en la zona de influencia de cada respuesta según lo indique la ratio decidendi de cada una de ellas, y se indican los puntos nodales de decisión asumidos por la Corte. Así entonces, las sentencias que señalen que la consulta previa debe ser 
realizada en todos los casos de implementación de medidas legislativas que puedan afectar derechos de las comunidades étnicas serán ubicadas en el extremo izquierdo de la gráfica. Las sentencias que indiquen que la consulta previa es obligatoria para la adopción de medidas legislativas solo cuando estas impliquen afectación directa y específica a los derechos de las comunidades se ubicarán en el costado derecho de la gráfica, pero cerca de su centro. Y, las sentencias que señalen que la consulta previa no es necesaria, se ubicarán en su extremo derecho.

La línea inicia con la sentencia SU-039 de 1997 (como sentencia fundadora de línea de carácter general) en la que se decide una acción de tutela en contra del Ministerio de Ambiente y la empresa Occidental de Colombia por el otorgamiento y ejecución de una licencia ambiental para exploración y explotación de hidrocarburos en territorios de la Comunidad U'wa. Si bien, en estricto sentido este fallo no debiera figurar en esta línea por no encuadrar exactamente dentro del conjunto de presupuestos fácticos señalados en la delimitación del problema, es relevante su análisis toda vez que en ella se estudia a profundidad el alcance de los derechos de las comunidades indígenas y se resalta la importancia de la consulta previa.

Posteriormente en 2001, con la revisión automática del proyecto de ley estatutaria para el artículo 176 de la Constitución relativo a la creación de una circunscripción especial para comunidades étnicas, minorías políticas y colombianos residentes en el extranjero, la Corte mediante Sentencia C-169, que decretó la constitucionalidad del proyecto de ley por considerar que dicha medida legislativa no afectaba de manera específica comunidades indígenas sino que se trataba del ejercicio de la facultad general de desarrollo de la Constitución, inició de forma específica la fundación de la línea sobre consulta previa al determinar que los derechos contenidos en el Convenio 169 de la OIT y en los artículos 7 y 330 de la CP son predicables de todas las minorías étnicas existentes en el territorio nacional y no solo de las comunidades indígenas.

En 2002, la Corte mediante sentencia C-418 continuó el proceso de afianzamiento de la línea al decidir la constitucionalidad condicionada de un artículo de la Ley 685 de 2001 sobre la creación de zonas mineras en territorios de las comunidades indígenas. Para la Corporación, es constitucional que en el trámite de creación de zonas mineras indígenas que adelante el Ministerio de Minas y Energía se realice la consulta previa a las comunidades dadas las consecuencias reales y directas que de dicha actuación pueden surgir para estas. Por esta razón, la Corte considera que la medida legislativa proyectada 
en la norma demandada será constitucional en la medida que se respete en el posterior trámite administrativo de declaración de zonas mineras, los derechos de las comunidades indígenas asentadas en la zona de influencia de los proyectos mineros. Obsérvese cómo con esta sentencia la Corte propone un punto intermedio entre las dos posibles posturas a asumir dentro de OP 2.

Ese mismo año, con sentencia C-891 al resolverse una acción de inconstitucionalidad en contra de varios artículos del Código Minero bajo el cargo general de no haberse efectuado la consulta previa a las comunidades indígenas, la Corte avanzó en la fundación de la línea al considerar que las autoridades competentes sí habían iniciado el trámite de consulta antes de la radicación del proyecto de ley ante el Congreso de la República.

En 2003, mediante sentencia SU-383 (la cual podría ser objetada de cierta manera por no decidir sobre la adopción de medidas legislativas), la Corte resolvió una acción de tutela interpuesta en contra de las actividades de erradicación de cultivos ilícitos existentes en el territorio nacional en el marco del Plan Colombia y en ella determinó que no era procedente la suspensión de las actividades de erradicación a pesar de que no se había adelantado consulta a las comunidades indígenas porque, si bien era evidente la posible afectación de los recursos naturales existentes en sus territorios, se trataba de una medida (administrativa) que en ejercicio de potestades soberanas había sido adoptada para la totalidad del territorio nacional en general. Aunque como en el caso de la SU-039 de 1997 esta sentencia no cumple con los presupuestos fácticos de selección señalados para la delimitación de la línea, vale la pena su inclusión dentro de esta porque: 1. A pesar de tratarse de medidas administrativas estas provienen de actividades relacionadas con el desarrollo de medidas legislativas; 2. A diferencia del fallo de los U'wa, en esta ocasión se ordenó la consulta sin que esto implicase por sí mismo la suspensión de la medida administrativa, lo cual ubica a esta sentencia en una posición más cercana al matiz de no necesidad de la consulta previa de OP 2; y 3. No es cierto que la consulta previa no aplique en adopción de medidas de cualquier tipo relacionadas con la erradicación de cultivos ilícitos existentes en territorios de las comunidades indígenas por tratarse precisamente de una actividad delictual, toda vez que para estas comunidades existen vínculos culturales y vitales con algunos de estos tipos de cultivos, como por ejemplo la coca y la marihuana (López, 2006, p. 169).

Cuatro años después mediante sentencia C-208 de 2007, la Corte analizó la presunta violación de los derechos de las comunidades indígenas a 
la educación y a la preservación de su cultura surgida de la adopción del Estatuto Nacional de Profesionalización de la Docencia y estableció la constitucionalidad condicionada de dicha norma al señalar que sería entendida en el sentido de que no aplicaría para el nombramiento de docentes en territorios indígenas y que, para tales casos se continuarían aplicando las normas generales contenidas en la Ley General de Educación sobre etno-educación.

En 2008, al analizarse una demanda de inconstitucionalidad en contra de la Ley General Forestal (L.1021/2006), bajo el cargo de violación al derecho fundamental a la consulta previa de comunidades étnicas, la Corte declaró su inexequibilidad total por considerar que en este caso sí se trataba de la adopción de una medida legislativa que de manera directa y particular afectaba recursos naturales existentes en territorios indígenas y que la no consulta a las comunidades antes de la radicación del proyecto ante el Congreso de la República constituía un vicio de forma que tenía repercusiones en el contenido material de la norma demandada.

Adicionalmente, (y esta es la razón para considerar que esta sentencia se erige como el fallo dominante de la línea) señaló que tratándose de medidas legislativas que puedan afectar derechos de las comunidades étnicas existen tres posibilidades de discusión cuando se cuestiona su constitucionalidad por presunta violación a la obligación de consultar a las comunidades. En primer lugar, cuando se trate de medidas legislativas, generales o específicas que afecten de manera directa la identidad cultural o la autonomía étnica de las comunidades. En segundo lugar, teniendo en cuenta que a la fecha no existía una norma específica que regulara lo atinente al desarrollo del proceso de consulta previa antes de presentarse el proyecto ante el Congreso, sería posible determinar que el contenido de la norma demandada no afecta de manera específica a las comunidades étnicas o que pudiendo afectarlas de cierta forma es posible salvar su contenido mediante el decreto de cláusulas de interpretación, exclusiones de comunidades diferenciadas, o inexequibilidades parciales (Posición intermedia de OP 2)). En tercer lugar, la Corte considera que cuando se trate de medidas legislativas de carácter general que implican cargas abstractas para la totalidad de los colombianos y para todo el territorio nacional, la obligación de la consulta a las comunidades se traslada a la expedición, creación e implementación de normas, actividades, planes, programas y proyectos que pretendan ejecutar de manera específica y directa los contenidos de la medida legislativa general cuando de ello puedan surgir afectaciones directas a las comunidades étnicas (Segunda posición de OP 2). 
La sentencia C-461 de 2008 contribuyó a la consolidación del segundo escenario de discusión señalado por la Corte en la sentencia C-030 de 2008. En esta oportunidad la Corporación al analizar la constitucionalidad del Plan Nacional de Desarrollo 2006-2010 (L.1151/2007) por vulneración del derecho a la consulta previa a las comunidades étnicas en el trámite prelegislativo de la norma, consideró que si bien la ley demandada no fue consultada a pesar de contener disposiciones que podían afectar a las comunidades, era posible decretar su constitucionalidad condicional.

Por su parte, la sentencia C-750 de 2008 consolidó el tercer escenario de discusión propuesto en la C-030 de 2008 y al declarar la constitucionalidad del Acuerdo Comercial entre Colombia y Estados Unidos (L.1143/2007) a través de revisión automática de constitucionalidad, consideró que la referida norma se ajustaba a la Carta Política a pesar de no haber sido consultada de manera previa a las comunidades indígenas toda vez que su contenido, a pesar de incluir un capítulo destinado a temas ambientales, es de carácter general y no afecta de forma específica y directa a las comunidades étnicas de Colombia.

En sentencia C-175 de 2009 la Corte analizó la constitucionalidad del Estatuto Nacional de Desarrollo Rural (L.1152/2007) impugnada mediante acción de inconstitucionalidad por considerarse que la no realización de la consulta previa a las comunidades indígenas en el trámite prelegislativo era violatorio de derechos fundamentales de estas minorías étnicas. Al respecto, la Corte consolidó el primer escenario de discusión surgido de la sentencia C-030 de 2008 y decretó la inexequibilidad total de la norma demandada al considerar que el Estatuto de Desarrollo Rural, a pesar de estar dirigido a la totalidad del territorio y la población colombiana, afectaba de manera directa y específica a las comunidades indígenas por estar localizadas precisamente en territorios considerados como rurales.

A partir de este momento, puede considerarse consolidada la línea jurisprudencial de la Corte Constitucional sobre la obligación de la consulta previa a las comunidades indígenas en materia de adopción de medidas legislativas que puedan afectar los recursos naturales existentes en su territorio y se puede observar cómo la amplitud de la obligación inicial de consulta, se ha extendido a todo tipo de comunidad étnica y aplica para todo tipo de medida legislativa que de manera específica y directa afecte los derechos de las comunidades en razón de su identidad cultural y autodeterminación étnica. 
También se ha podido observar que desde el principio no ha sido recibida por la Corte la opción polar 1, según la cual la consulta es obligatoria en todo caso de medidas legislativas que afecten recursos naturales existentes en los territorios indígenas. Sino que se ha optado más bien por acoger una postura moderada en la que la obligación de realización de la consulta está sujeta a la valoración que se haga de los derechos e intereses que puedan resultar afectados de manera directa y específica con la adopción de la medida.

Ahora bien, teniendo en cuenta que del análisis de los nichos citacionales de primer y segundo nivel surgieron otras sentencias, además de las ya mencionadas, que fueron clasificadas como de conformación, resta referirnos a ellas con la salvedad que serán agrupadas conforme a los puntos nodales de decisión (o escenarios de discusión) establecidos en la sentencia C-030 de 2008.

En primer lugar, siguiendo la posición que señala la obligatoriedad de la consulta so pena de declaración total de inexequibilidad por considerarse vulnerados de manera directa y específica derechos de las comunidades étnicas al omitirse la consulta en el trámite prelegislativo de la norma demandada (primer escenario de discusión o punto nodal $A$ ), se encuentran las sentencias C-615 de 2009 y C-702 de 2010.

En segundo término, conforme a la posición que señala la constitucionalidad de ciertas medidas legislativas cuando no ha sido posible adelantar su consulta previa en la etapa prelegislativa y permite el saneamiento de dicha omisión mediante toma de decisiones relacionadas con declaratorias de exequibilidad condicionadas o inexequibilidades parciales (Punto nodal B o segundo escenario de discusión), la Corte profirió la sentencia C-196 de 2012. En ella, en ejercicio de revisión automática de constitucionalidad, se declaró la exequibilidad condicionada de la L.1458/2011 por la cual se aprobaba el Convenio Internacional de Maderas Tropicales, en el entendido de que si bien no se había efectuado el trámite de consulta previa en sede prelegislativa, era obligación del Gobierno nacional realizar la correspondiente consulta previa a las comunidades étnicas cuando se crearan, expidieran o implementaran medidas legislativas o administrativas encaminadas a la ejecución de los preceptos contenidos en el Tratado. Este fallo contó con dos salvamentos de voto. El primero del magistrado Palacio, para quien la ley debió ser declarada inexequible en su totalidad dado que por su contenido material la consulta previa era obligatoria y su ausencia no era saneable con la llamada declaración de interpretación incluida en el texto de ratificación del Tratado. El 
segundo, del magistrado Pinilla, señala que la ley debió ser declarada inexequible en su totalidad porque la obligación de efectuar la consulta iba más allá de la sede prelegislativa.

En tercera instancia, aparece la posición que establece que la obligación de la consulta previa se traslada del proceso de adopción de medidas legislativas generales al trámite de adopción de medidas legislativas o administrativas especiales cuando por acción de la generalidad de aquellas no se infiere afectación directa y específica para las comunidades étnicas y, solo cuando se llega a niveles de su materialización práctica o implementación se advierte esta vulneración (Punto nodal $\mathrm{C}$ o tercer escenario de discusión). En este sentido la Corte ha proferido las sentencias C-027 de 2011 (L.1258/2008 aprobatoria del Convenio básico de cooperación científica y tecnológica entre Guatemala y Colombia), C-332/2014 (L.1665/2013 aprobatoria del Estatuto de la Agencia Internacional de Energías Renovables), y, C-163/2015 (L.1721/2014 aprobatoria del Acuerdo marco de la Alianza del Pacífico).

Dicho todo lo anterior, resta ahora proceder a la representación gráfica de la telaraña de la línea. Así, siguiendo a López Medina (2006, p. 169), la telaraña podría ser dibujada así:

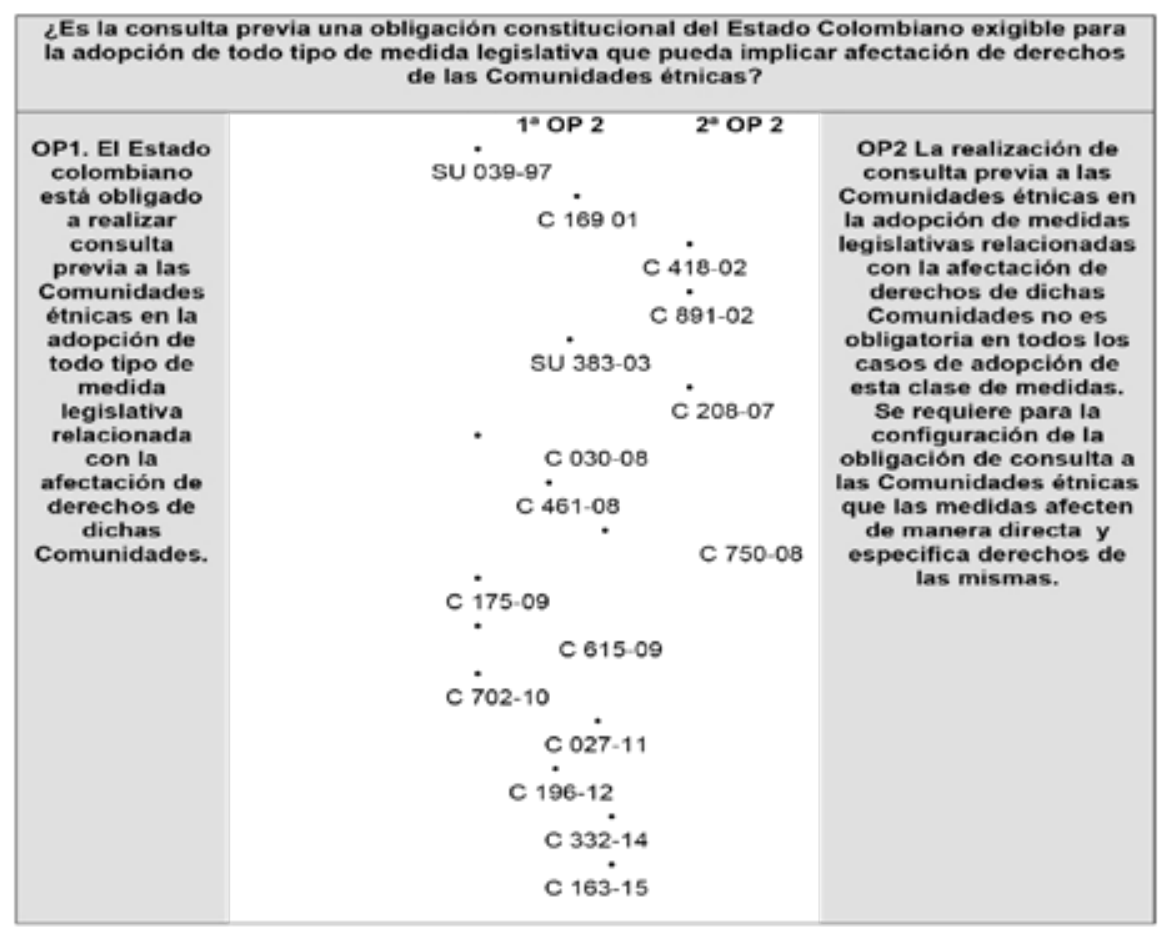

Figura No. 7. La telaraña de la línea jurisprudencial

Fuente propia 
Y, en igual sentido, los puntos nodales de decisión podrían ser expresados gráficamente así:
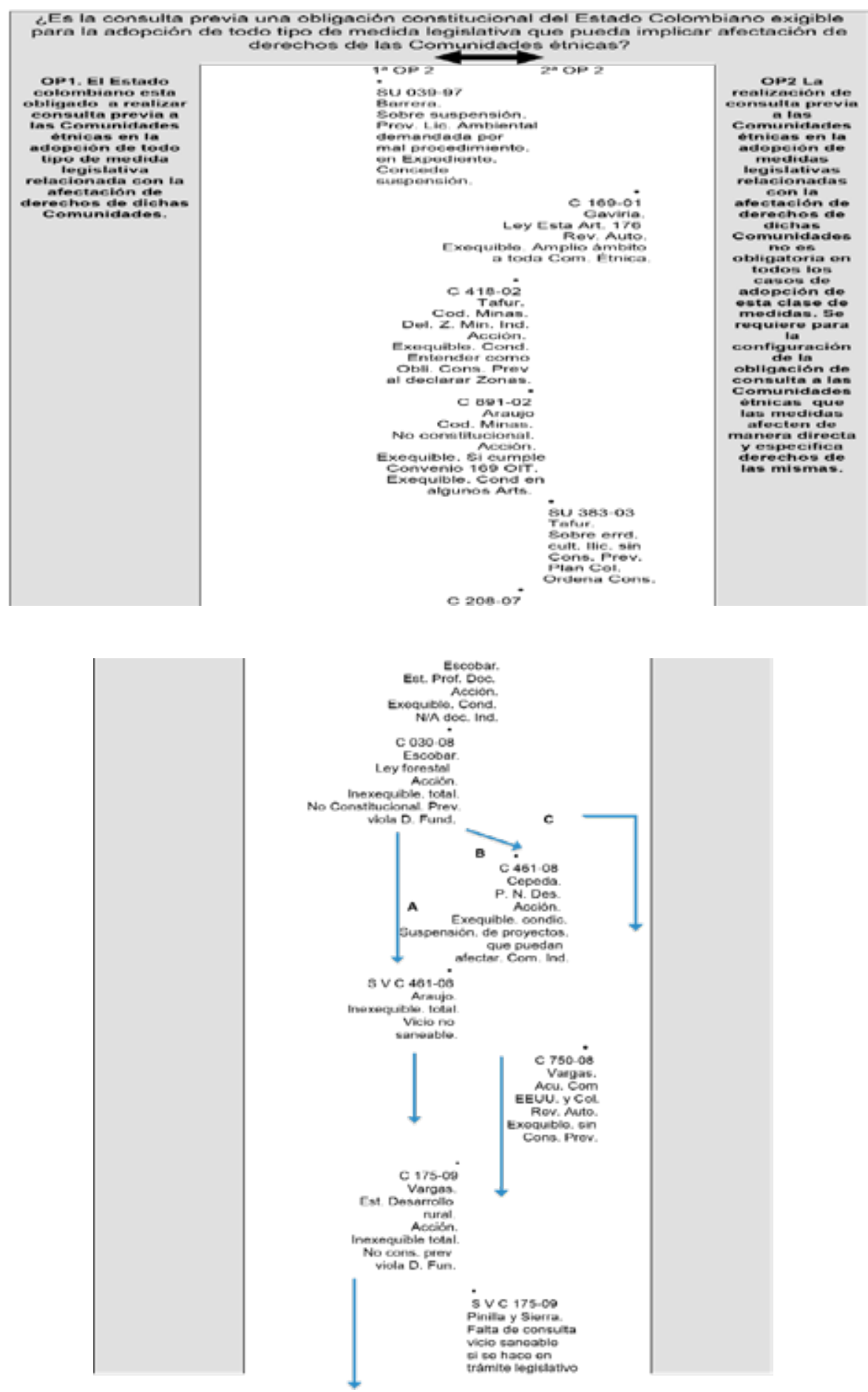

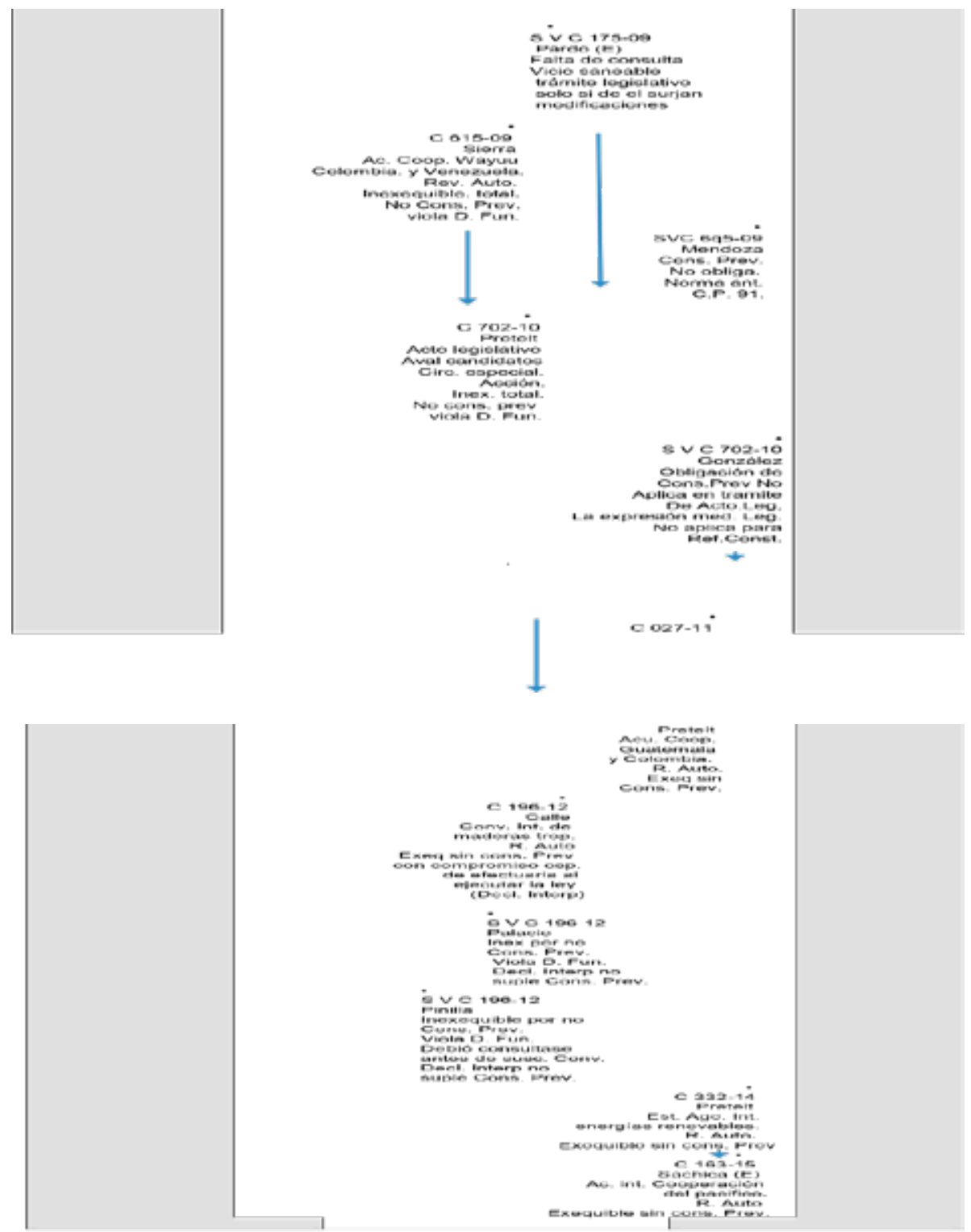

Figura No. 8. Puntos nodales de decisión Fuente propia

\section{CONCLUSIONES}

Con fundamento en toda la exposición, puede indicarse a manera de conclusión que de la línea jurisprudencial que la Corte Constitucional de Colombia ha edificado en torno de la obligatoriedad de realizar consulta previa a las comunidades étnicas cuando se trate de la adopción de medidas legislativas que puedan afectar sus derechos, surgen las siguientes subreglas de derecho de índole jurisprudencial: 
1. La consulta previa es un derecho constitucional de todas las comunidades étnicas que habitan en Colombia.

2. La consulta previa aplica a todo tipo de medida legislativa o administrativa que pueda afectar derechos de las comunidades étnicas.

3. La consulta previa está instituida como mecanismo de defensa de los derechos de las comunidades étnicas en razón de su identidad cultural y autodeterminación política.

4. La consulta previa es un derecho fundamental de las comunidades étnicas que pertenece al bloque de constitucionalidad.

5. El derecho a la consulta previa puede ser protegido por vía de acción de tutela y por vía de acción de inconstitucionalidad según la configuración de los presupuestos fácticos que motiven su vulneración.

6. En materia de medidas legislativas la consulta previa es obligatoria cuando con la adopción de ellas resulten afectaciones directas y específicas para las comunidades étnicas.

7. Para determinar la afectación que una medida legislativa pueda tener sobre los derechos de las comunidades étnicas se debe valorar el contenido material de la medida y sus destinatarios. Se debe valorar en consecuencia, si dicha medida implica afectaciones directas a los derechos de las comunidades étnicas y si estas son específicas para tales poblaciones al punto de ejercer presión sobre sus formas de vida ancestral.

8. La falta de consulta en el trámite prelegislativo de una medida constituye un vicio de forma que se transmite al contenido material de la norma en creación.

9. La consulta previa en el trámite legislativo debe presentarse antes de la radicación del proyecto de medida ante el Congreso de la República. Así, la consulta debe realizarse en la etapa prelegislativa.

10. Cuando la medida legislativa que afecte de manera directa y específica a las comunidades étnicas no sea consultada en la etapa prelegislativa procederá su declaratoria de inexequibilidad por violación de derechos fundamentales de las comunidades étnicas.

11. La consulta previa de medidas legislativas no puede surtirse después de iniciado el trámite legislativo.

12. La falta de acuerdo en el desarrollo de la consulta previa dentro de un trámite prelegislativo no implica un poder de veto en favor de las comunidades étnicas y en contra de las autoridades estatales.

13. La consulta previa no es obligatoria en la fase de negociación de un 
Tratado internacional que implique afectaciones directas y específicas para las comunidades étnicas.

14. La consulta previa en la aprobación de Tratados internacionales que afecten directa y específicamente a comunidades étnicas debe realizarse entre el momento de suscripción del instrumento y la radicación del proyecto de ley por el cual se aprueba el mismo.

15. Teniendo en cuenta que no existen normas legisladas que regulen el procedimiento de la consulta previa, es posible decretar en el trámite de una acción de inconstitucionalidad una omisión legislativa relativa que permita sanear el vicio de inexequibilidad con la aplicación del principio de conservación del derecho mediante declaraciones de constitucionalidad condicionada o inexequibilidad parcial.

16. La adopción de medidas legislativas que sean de contenido general y abstracto no requieren la práctica de consulta previa en la etapa prelegislativa. La consulta previa será obligatoria cuando de la adopción de medidas legislativas generales se desprendan otras medidas (legislativas o administrativas) que sí afecten de manera directa y específica a las comunidades étnicas.

\section{REFERENCIAS BIBLIOGRÁFICAS}

\section{A. Bibliografía impresa}

López, D. (2006). El derecho de los jueces. 2da. Ed. Bogotá: Legis.

\section{B. Referencias de sentencias de Tribunales o altas Cortes}

Colombia. Corte Constitucional Colombiana. Sentencia SU-039 de 1997. M.P. Antonio Barrera Carbonell.

Colombia. Corte Constitucional Colombiana. Sentencia SU-510 de 1998. M.P. Eduardo Cifuentes Muñoz.

Colombia. Corte Constitucional Colombiana. Sentencia T-634 de 1999. M.P. Alejandro Martínez Caballero.

Colombia. Corte Constitucional Colombiana. Sentencia C-169 de 2001. M.P. Carlos Gaviria Díaz.

Colombia. Corte Constitucional Colombiana. Sentencia C-418 de 2002. M.P. Álvaro Tafur Galvis.

Colombia. Corte Constitucional Colombiana. Sentencia C-891 de 2002. M.P. Jaime Áraújo Renteria.

Colombia. Corte Constitucional. Sentencia C-620 de 2003. M.P. Marco Gerardo Monroy Cabra.

Colombia. Corte Constitucional Colombiana. Sentencia SU-383 de 2003. M.P. Álvaro Tafur Galvis.

Colombia. Corte Constitucional Colombiana. Sentencia T-955 de 2003. M.P. Álvaro Tafur Galvis. 
Colombia. Corte Constitucional Colombiana. Sentencia C-401 de 2005. M.P. Manuel José Cepeda Espinosa.

Colombia. Corte Constitucional Colombiana. Sentencia T-778 de 2005. M.P. Manuel José Cepeda Espinosa.

Colombia. Corte Constitucional Colombiana. Sentencia T-382 de 2006. M.P. Clara Inés Vargas Hernández.

Colombia. Corte Constitucional Colombiana. Sentencia T-704 de 2006. M.P. Humberto Antonio Sierra Porto.

Colombia. Corte Constitucional Colombiana. Sentencia C-208 de 2007. M.P. Rodrigo Escobar Gil.

Colombia. Corte Constitucional Colombiana. Sentencia C-030 de 2008. M.P. Rodrigo Escobar Gil.

Colombia. Corte Constitucional Colombiana. Sentencia C-461 de 2008. M.P. Manuel José Cepeda Espinosa.

Colombia. Corte Constitucional Colombiana. Sentencia C-750 de 2008. M.P. Clara Inés Vargas Hernández.

Colombia. Corte Constitucional Colombiana. Sentencia C-175 de 2009. M.P. Luis Ernesto Vargas Silva.

Colombia. Corte Constitucional Colombiana. Sentencia T-154 de 2009. M.P. Nilson Pinilla Pinilla.

Colombia. Corte Constitucional Colombiana. Sentencia T-973 de 2009. M.P. Mauricio Gonzales Cuervo.

Colombia. Corte Constitucional Colombiana. Sentencia C-615 de 2009. M.P. Humberto Antonio Sierra Porto.

Colombia. Corte Constitucional Colombiana. Sentencia C-702 de 2010. M.P. José Ignacio Pretelt Chaljub.

Colombia. Corte Constitucional Colombiana. Sentencia C-027 de 2011. M.P. Jorge Ignacio Pretelt Chaljub.

Colombia. Corte Constitucional Colombiana. Sentencia T-907 de 2011. M.P. Jorge Ignacio Pretelt Chaljub.

Colombia. Corte Constitucional Colombiana. Sentencia C-196 de 2012. M.P. María Victoria Calle Correa.

Colombia. Corte Constitucional Colombiana. Sentencia C-332 de 2014. M.P. Jorge Ignacio Pretelt Chaljub.

Colombia. Corte Constitucional Colombiana. Sentencia C-163 de 2015. M.P. Martha Victoria Sáchica Méndez.

\section{Referencias de leyes y convenios}

Colombia. Constitución Política Nacional de 1991. Bogotá: Editorial Legis.

Colombia. Ley 165 de 1994. Bogotá: Editorial Leyer.

Colombia. Ley 70 de 1993. Bogotá: Editorial Leyer.

Colombia. Ley 99 de 1993. Bogotá: Editorial Leyer.

Colombia. Ley 1021 de 2006. Bogotá: Editorial Leyer.

Colombia. Ley 1143 de 2007. Bogotá: Editorial Leyer. 
Colombia. Ley 1151 de 2007. Bogotá: Editorial Leyer.

Colombia. Ley 1152 de 2007. Bogotá: Editorial Leyer.

Colombia. Ley 1258 de 2008. (Aprobatoria del Convenio básico de cooperación científica y tecnológica entre Guatemala y Colombia). Bogotá: Editorial Leyer.

Colombia. Ley 1437 de 2011. Bogotá: Editorial Legis.

Colombia. Ley 1458 de 2011. Bogotá: Editorial Legis.

Colombia. Ley 1665 de 2013. (Aprobatoria del Estatuto de la Agencia Internacional de Energías Renovables). Bogotá: Editorial Leyer.

Colombia. Ley 1721 de 2014. Bogotá: Editorial Leyer.

Convenio 169 de la OIT (ratificado por Colombia mediante L.21/1991). 